\title{
Efficacy and tolerability of amlodipine plus olmesartan medoxomil in patients with difficult-to-treat hypertension
}

\author{
SG Chrysant ${ }^{1}$, J Lee ${ }^{2}$, M Melino ${ }^{2}$, S Karki ${ }^{2}$ and R Heyrman ${ }^{2}$ \\ ${ }^{1}$ Department of Cardiology and Hypertension, Oklahoma Cardiovascular and Hypertension Center and the \\ University of Oklahoma School of Medicine, Oklahoma City, OK, USA and ${ }^{2}$ Clinical Development, Daiichi \\ Sankyo Pharma Development, Edison, NJ, USA
}

\begin{abstract}
Hypertension is particularly prevalent in patients aged $\geqslant 65$ years, those with a body mass index $\geqslant 30 \mathrm{~kg} \mathrm{~m}^{-2}$, Blacks and those with type II diabetes. Here we report a prespecified secondary analysis of the efficacy of amlodipine (10 $\left.\mathrm{mg} \mathrm{day}^{-1}\right)$, olmesartan medoxomil $\left(40 \mathrm{mg} \mathrm{day}^{-1}\right)$, a combination of the two and placebo in these subgroups. Patients were randomized to treatment for $\mathbf{8}$ weeks. The primary efficacy endpoint was the change from baseline in mean seated diastolic blood pressure (DBP). Secondary efficacy endpoints included the change from baseline in mean seated systolic BP (SBP), proportions of patients achieving BP goal $(<140 / 90 \mathrm{~mm} \mathrm{Hg}$ or $<130 / 80 \mathrm{~mm} \mathrm{Hg}$ in patients with diabetes), and the number and percentage of patients achieving a range of BP targets. Safety and tolerability of amlodipine $\mathbf{5}$ and $\mathbf{1 0} \mathrm{mg}$, olmesartan medoxomil $\mathbf{1 0}$, 20 and $40 \mathrm{mg}$, and all possible combinations of the
\end{abstract}

two were also assessed. For each prespecified subgroup, all active treatments resulted in significant BP reductions from baseline $(P<0.05)$. The antihypertensive effect of the combination of amlodipine + olmesartan medoxomil was generally greater than the constituent amlodipine or olmesartan medoxomil monotherapies, regardless of subgroup. In general, more patients receiving combination therapy achieved BP goal than those treated with monotherapies. The safety and tolerability of combinations were similar to monotherapies across the subgroups. These results suggest that the combination of amlodipine + olmesartan medoxomil provides a safe and effective option for the treatment of hypertension in challenging patient populations.

Journal of Human Hypertension (2010) 24, 730-738; doi:10.1038/jhh.2010.5; published online 18 February 2010

Keywords: angiotensin receptor blocker; calcium channel blocker; elderly; obesity; race; type II diabetes

\section{Introduction}

It is well established that effective blood pressure (BP) control reduces the risk of cardiovascular disease and stroke in patients with hypertension. ${ }^{1,2}$ For every $20 \mathrm{~mm} \mathrm{Hg}$ decrease in systolic BP (SBP), there are 30 and $40 \%$ reductions in ischaemic heart disease and stroke mortality, respectively. ${ }^{3}$

However, only a small proportion of patients achieve BP goal $(<140 / 90 \mathrm{~mm} \mathrm{Hg}$ or $<130 /$ $80 \mathrm{~mm} \mathrm{Hg}$ in patients with diabetes) with antihypertensive monotherapy. ${ }^{1,2}$ The Seventh report of the Joint National Committee on Prevention, Detection, Evaluation, and Treatment of High Blood Pressure (JNC 7) and the European Societies of Hypertension and Cardiology guidelines recognize that in the

Correspondence: Dr SG Chrysant, Oklahoma Cardiovascular and Hypertension Center, 5850 West Wilshire Boulevard, Oklahoma City, OK 73132, USA.

E-mail: schrysant@yahoo.com

Received 11 July 2009; revised 18 November 2009; accepted 10 January 2010; published online 18 February 2010 majority of patients, combination therapy will be required. ${ }^{1,2}$

The prevalence of hypertension (BP $\geqslant 140$ / $90 \mathrm{~mm} \mathrm{Hg}$ or $\geqslant 130 / 80 \mathrm{~mm} \mathrm{Hg}$ in patients with diabetes) is approximately $33 \%$ in the general population and even higher in certain patient populations. ${ }^{4,5}$ In the elderly, $63.6 \%$ of women and $73.9 \%$ of men have hypertension. ${ }^{4,5}$ Hypertension prevalence is also higher in Blacks (41.4\%), patients with diabetes $(76.8 \%)$ and those who are obese (body mass index (BMI) $\geqslant 30 \mathrm{~kg} \mathrm{~m}^{-2} ; 40.8 \%$ ). ${ }^{5-8} \mathrm{In}$ the case of elderly or patients with diabetes, this is due, in part, to arterial stiffness as a consequence of the pathobiology of ageing or diabetes. ${ }^{9,10}$ Causes of the increased prevalence of hypertension in Blacks have not been fully elucidated, though it appears that physiological factors may have a part. ${ }^{11}$ In addition, Black children have significantly higher BP than age-matched Caucasian children of $<10$ years of age, and Blacks with hypertension generally present with more severe disease., ${ }^{4,5}$ In obese patients, the renin-angiotensin system may be dysregulated contributing to the development of hypertension. ${ }^{12}$ 
Treating hypertension in patients with diabetes is challenging because of a stringent BP goal $(<130 /$ $80 \mathrm{~mm} \mathrm{Hg}$ ) that has been shown to reduce the progression of diabetic nephropathy onto end-stage renal disease and other complications of diabetes. ${ }^{1,2,13}$ Treatment guidelines from scientific committees recommend the use of two or more antihypertensive agents for control of BP in Blacks or patients with diabetes, and generally recommend the use of two or more antihypertensive agents if BP is $\geqslant 20 / 10 \mathrm{~mm} \mathrm{Hg}$ above goal in any patient. ${ }^{1,2,13}$

Combinations of angiotensin receptor blockers (ARBs) and calcium channel blockers (CCBs) are recognized by the European Society of Hypertension and the European Society of Cardiology as effective and well-tolerated therapeutic options. ${ }^{2}$ It has been shown that combination therapy with an ARB or an angiotensin-converting enzyme inhibitor with a CCB may minimize the adverse effects of the CCB, such as peripheral oedema. ${ }^{14,15}$ ARBs also provide protection against renal and cardiac end-organ failure, ${ }^{16}$ which is of particular importance in patients with diabetes and hypertension. A recent long-term clinical outcomes study, ACCOMPLISH (Avoiding Cardiovascular Events in Combination Therapy in Patients Living With Systolic Hypertension), has shown that the combination of renin-angiotensin system blockade (angiotensin-converting enzyme inhibitor-benazepril) with a CCB (amlodipine) was more effective in reducing cardiovascular complications than the combination of renin-angiotensin system blockade (benazepril) with a diuretic (hydrochlorothiazide). ${ }^{17,18}$

The results of the $\mathrm{COACH}$ (Combination of Olmesartan Medoxomil and Amlodipine Besylate in Controlling High Blood Pressure) study, a clinical trial that assessed the efficacy and safety of amlodipine besylate (dihydropyridine CCB) in combination with olmesartan medoxomil (ARB) in patients with mild-to-severe hypertension, have been published elsewhere. ${ }^{19}$ Here we report a prespecified subgroup analysis of the COACH study in patients with diabetes, Blacks, elderly $(\geqslant 65$ years) patients and those who are overweight/obese with a $\mathrm{BMI} \geqslant 30 \mathrm{~kg} \mathrm{~m}^{-2}$.

\section{Materials and methods}

\section{Study population}

This was an 8-week multicenter, randomized, double-blind, factorial design study conducted at 172 sites in the United States of America. Inclusion criteria have been described in detail elsewhere. ${ }^{19}$ Briefly, patients who were aged $\geqslant 18$ years with both a mean seated diastolic BP (SeDBP) of 95$120 \mathrm{~mm} \mathrm{Hg}$ from 1 week before randomization and at the randomization visit with a mean SeDBP difference of $\leqslant 10 \mathrm{~mm} \mathrm{Hg}$ from the two separate visits were randomized to treatment. Subgroup analyses were carried out for each of the following variables: diabetes status (yes/no), age $(<65$ years and $\geqslant 65$ years) and baseline BMI $\left(\geqslant 30 \mathrm{~kg} \mathrm{~m}^{-2}\right.$, $<30 \mathrm{~kg} \mathrm{~m}^{-2}$ ). A further subgroup analysis was made on the basis of race (Black/non-Black).

Patients with a history of cardiovascular disease, SeDBP $>120 \mathrm{~mm} \mathrm{Hg}$, uncontrolled diabetes (glycosylated haemoglobin (HbA1c) $>9.0 \%$ ), history of drug or alcohol abuse, those who smoked $>1$ pack of cigarettes per day, and those with any medical condition judged by investigators to possibly jeopardize the evaluation of efficacy and safety of therapy were excluded from the study. Patients were also excluded for whom participation in the study constituted a significant risk.

The study was conducted in accordance with the institutional review board committee regulations and the Declaration of Helsinki. Written informed consent was obtained from each patient at screening.

\section{Study design}

Patients who are currently not taking any antihypertensive medications (for example, naïve) or those who have completed a washout of their current antihypertensive medications and who have met BP enrollment criteria were randomized to 1 of the 12 treatment regimens: placebo, amlodipine monotherapy $\left(5\right.$ or $\left.10 \mathrm{mg} \mathrm{day}^{-1}\right)$, olmesartan medoxomil monotherapy (10, 20 or $40 \mathrm{mg} \mathrm{day}^{-1}$ ) or combination therapy with amlodipine + olmesartan medoxomil, including all possible dose combinations of the monotherapy groups. ${ }^{19}$ Randomization included a stratification based on age $(<65$ years and $\geqslant 65$ years) and diabetes status. Efficacy data reported here comprise the highest US Food and Drug Administration-approved dosage of amlodipine $\left(10 \mathrm{mg} \mathrm{day}^{-1}\right)$ combined with olmesartan medoxomil (40 mg day ${ }^{-1}$ ), the constituent monotherapies and placebo. Efficacy data are not reported for patients receiving olmesartan medoxomil $10 \mathrm{mg} \mathrm{day}^{-1}$, $20 \mathrm{mg}$ day $^{-1}$, amlodipine $5 \mathrm{mg}$ day $^{-1}$, amlodipine + olmesartan medoxomil $5+10 \mathrm{mg} \mathrm{day}^{-1}, \quad 5+$ $20 \mathrm{mg} \mathrm{day}^{-1}, 5+40 \mathrm{mg} \mathrm{day}^{-1}, 10+10 \mathrm{mg} \mathrm{day}^{-1}$ and $10+20 \mathrm{mg} \mathrm{day}^{-1}$ but are available in Supplementary Tables 1 and 2.

Patients were instructed to take their medication at the same time each day $( \pm 2 \mathrm{~h})$. Clinic visits were scheduled to allow a trough BP measurement $24 \mathrm{~h}$ after the normal dosing time, and patients were refrained from taking their daily medication until all the measurements were completed.

Therapeutic efficacy and safety were evaluated at weeks 2, 4, 6 and 8. Vital signs, including BP and heart rate, were obtained at all scheduled visits. BP was assessed at all participating sites using an automated BP-monitoring device (Omron Model HEM-705CP). After a 5-min rest period, three separate seated BP (SeBP) measurements were taken at $1 \mathrm{~min}$ apart, and the mean of the three readings was recorded. 
For the efficacy evaluation, the intent-to-treat population was the primary-analysis population and included all the patients who took at least one dose of double-blind study medication and had one post-baseline BP measurement. Patients who took at least one dose of randomized, double-blind study medication were included in the safety population.

\section{Efficacy variables}

The primary efficacy variable was the change from baseline in mean SeDBP at week 8, using the last observation carried forward (LOCF) for patients who did not complete the study protocol (week 8/LOCF). The secondary efficacy variable was the change from baseline in mean SeSBP at week 8/LOCF. Other efficacy variables assessed included the following: change from baseline in mean SeDBP and mean SeSBP at weeks $2,4,6$ and 8 without LOCF; proportion of patients achieving BP goal (combined term of $<140 / 90 \mathrm{~mm} \mathrm{Hg}$ or $<130 / 80 \mathrm{~mm} \mathrm{Hg}$ for patients with diabetes) at weeks $2,4,6,8$ and 8/LOCF; proportion of patients achieving BP targets at week 8/LOCF $(<140 / 90 \mathrm{~mm} \mathrm{Hg}$ and $<120 /$ $80 \mathrm{~mm} \mathrm{Hg}$ ); and comparison of reductions in mean SeSBP and mean SeDBP between combination therapy and its constituent monotherapy components. These efficacy assessments were also applied to prespecified subgroups including age $(<65$ years, $\geqslant 65$ years), race (Black and non-Black), diabetes status and baseline BMI $\left(<30 \mathrm{~kg} \mathrm{~m}^{-2}\right.$ and $\geqslant 30 \mathrm{~kg} \mathrm{~m}^{-2}$ ).

\section{Safety variables}

Adverse events (AEs) and serious AEs were recorded at all visits. This study used the definition of a serious AE provided by the US Food and Drug Administration. The occurrence and severity of peripheral oedema were proactively assessed at all scheduled clinic visits, and when oedema was present, the severity was rated on a 5-point scale based on the following categories: no oedema; mild pitting, slight indentation; moderate pitting or indentation; deep pitting, indentation remains; and leg remains swollen. Investigators were encouraged to report increases in the severity of oedema as AEs. Safety data are presented for all monotherapies, drug combinations and placebo.

\section{Statistical analysis}

Summary statistics were determined for baseline, endpoint, and the mean change in SeDBP and SeSBP at week 8/LOCF for each level of the subgroup variables. One-sided $P$-values for testing the significance of combination therapy versus each monotherapy component were derived from an analysis of covariance model that used treatment group, subgroup and treatment-by-subgroup interaction as fixed effects and study baseline $\mathrm{BP}$ as a covariate. As $P$-values were one-sided for this comparison, differences between combination therapies and monotherapy components were significant if $P<0.025$. Though the analyses were prespecified, the study was only powered to show statistical differences between combination therapy and its constituent monotherapy components in the overall study cohort and was not powered to show statistical significance within the treatment regimens in each of the prespecified subgroups.

All SeSBP and SeDBP reductions are reported here as least-squares means. Least-squares means, corresponding standard errors, and 95\% two-sided confidence intervals, as well as the difference in least-squares means, corresponding standard error, and $95 \%$ two-sided confidence intervals, were also derived from this analysis of covariance model. A $\chi^{2}$-test was employed to determine the significance of differences between treatment groups for the number of patients reaching $\mathrm{BP}$ goal. One-sided $P$-values were obtained from individual Fisher's exact tests.

\section{Results}

A total of 4234 patients were screened, 1940 patients were randomized and 1689 completed the 8-week double-blind portion of the study. ${ }^{19}$ The mean age for the study cohort was 54.0 years, $19.8 \%$ were $\geqslant 65$ years, $54.3 \%$ were male and $24.8 \%$ were Black. The mean baseline BMI was $33.5 \mathrm{~kg} \mathrm{~m}^{-2}, 64.7 \%$ of patients were classified as obese (BMI $\geqslant 30 \mathrm{~kg} \mathrm{~m}^{-2}$ ) and patients with diabetes comprised $13.5 \%$ of the total study population. The overall mean baseline SeBP was $163.8 / 101.6 \mathrm{~mm} \mathrm{Hg}$. The baseline demographics for each subgroup are presented in Table 1.

For each subgroup analysed, by week $8 / \mathrm{LOCF}$, SeDBP and SeSBP were significantly reduced from baseline for all olmesartan medoxomil monotherapy $(P<0.05)$, amlodipine monotherapy $(P<0.0001)$ and amlodipine + olmesartan medoxomil $(P<0.0001)$ treatment regimens. Generally, the greatest reduction from baseline occurred in patients receiving amlodipine + olmesartan medoxomil $10+40 \mathrm{mg} \mathrm{day}^{-1}$. These efficacy data for each subgroup and the comparisons with amlodipine $10 \mathrm{mg} \mathrm{day}^{-1}$, olmesartan medoxomil $40 \mathrm{mg} \mathrm{day}^{-1}$ and placebo are presented (Figure 1).

Age

At week 8/LOCF, changes in mean SeBP were $-29.1 /-18.5$ and $-33.9 /-20.9 \mathrm{~mm} \mathrm{Hg}$ for patients aged $<65$ years and $\geqslant 65$ years, respectively, who received amlodipine + olmesartan medoxomil $10+40 \mathrm{mg} \mathrm{day}^{-1}$ (Figure 1). All SeBP changes were significant for combination therapy compared with the monotherapy components with the exception of the reduction in mean SeSBP in patients aged $\geqslant 65$ years versus amlodipine. The combined BP goal of $<140 / 90 \mathrm{~mm} \mathrm{Hg}$, and $<130 / 80 \mathrm{~mm} \mathrm{Hg}$ for those 
Table 1 Baseline patient demographics according to subgroup (intent-to-treat population)

\begin{tabular}{|c|c|c|c|c|c|c|c|c|}
\hline & \multicolumn{2}{|c|}{ Age } & \multicolumn{2}{|c|}{ Race } & \multicolumn{2}{|c|}{ Diabetes status } & \multicolumn{2}{|c|}{$B M I$} \\
\hline & $\begin{array}{l}<65 \text { years } \\
(\mathrm{n}=1541)\end{array}$ & $\begin{array}{l}\geqslant 65 \text { years } \\
(\mathrm{n}=382)\end{array}$ & $\begin{array}{c}\text { Black } \\
(\mathrm{n}=474)\end{array}$ & $\begin{array}{l}\text { Non-Black } \\
(\mathrm{n}=1449)\end{array}$ & $\begin{array}{l}\text { Diabetes } \\
(\mathrm{n}=258)\end{array}$ & $\begin{array}{l}\text { No diabetes } \\
(\mathrm{n}=1665)\end{array}$ & $\begin{array}{l}<30 \mathrm{~kg} \mathrm{~m}^{-2} \\
(\mathrm{n}=658)\end{array}$ & $\begin{array}{l}\geqslant 30 \mathrm{~kg} \mathrm{~m}^{-2} \\
(n=1251)\end{array}$ \\
\hline Mean age, years \pm s.d. & $50.2 \pm 8.5$ & $69.8 \pm 3.3$ & $50.8 \pm 10.8$ & $55.1 \pm 11.0$ & $57.0 \pm 10.7$ & $53.6 \pm 11.1$ & $56.4 \pm 11.1$ & $52.8 \pm 10.9$ \\
\hline Aged $\geqslant 65$ years, $n(\%)$ & NA & $382(100 \%)$ & $62(13.1 \%)$ & $320(22.1 \%)$ & $73(28.3 \%)$ & $309(18.6 \%)$ & $179(27.2 \%)$ & $199(15.9 \%)$ \\
\hline Males, $n(\%)$ & $836(54.3 \%)$ & $209(54.7 \%)$ & $191(40.3 \%)$ & $854(58.9 \%)$ & $151(58.5 \%)$ & $894(53.7 \%)$ & $385(58.5 \%)$ & $649(51.9 \%)$ \\
\hline $\begin{array}{l}\text { Hispanic or Latino, } \\
n(\%)\end{array}$ & $195(12.7 \%)$ & $46(12.0 \%)$ & $15(3.2 \%)$ & $226(15.6 \%)$ & $54(20.9 \%)$ & $187(11.2 \%)$ & $88(13.4 \%)$ & $151(12.1 \%)$ \\
\hline Black, $n(\%)$ & $412(26.7 \%)$ & $62(16.2 \%)$ & $474(100 \%)$ & NA & $66(25.6 \%)$ & $408(24.5 \%)$ & $143(21.7 \%)$ & $328(26.2 \%)$ \\
\hline Diabetes, $n(\%)$ & $185(12.0 \%)$ & $73(19.1 \%)$ & $66(13.9 \%)$ & $192(13.3 \%)$ & $258(100 \%)$ & NA & $57(8.7 \%)$ & $199(15.9 \%)$ \\
\hline $\begin{array}{l}\text { Previous antihyper- } \\
\text { tensive therapy, } n(\%)\end{array}$ & $962(62.4 \%)$ & $304(79.6 \%)$ & $324(68.4 \%)$ & $942(65.0 \%)$ & $191(74.0 \%)$ & $1075(64.6 \%)$ & $445(67.6 \%)$ & $812(64.9 \%)$ \\
\hline Oedema present, $n(\%)$ & $199(12.9 \%)$ & $64(16.8 \%)$ & $75(15.9 \%)$ & $188(13.0 \%)$ & $51(19.8 \%)$ & $212(12.7 \%)$ & $38(5.8 \%)$ & $224(17.9 \%)$ \\
\hline Mean BMI, $\mathrm{kg} \mathrm{m}^{-2} \pm$ s.d. & $33.9 \pm 7.2$ & $31.6 \pm 6.4$ & $34.6 \pm 7.9$ & $33.1 \pm 6.8$ & $35.2 \pm 6.8$ & $33.2 \pm 7.1$ & $26.7 \pm 2.6$ & $37.0 \pm 6.0$ \\
\hline $\mathrm{BMI} \geqslant 30 \mathrm{~kg} \mathrm{~m}^{-2}, n(\%)$ & $1052(68.3 \%)$ & $199(52.1 \%)$ & $328(69.2 \%)$ & $923(63.7 \%)$ & $199(77.1 \%)$ & $1052(63.2 \%)$ & NA & $1251(100 \%)$ \\
\hline \multicolumn{9}{|l|}{ Baseline BP } \\
\hline Mean SeSBP, mmHg \pm s.d. & $161.4 \pm 14.8$ & $173.6 \pm 17.4$ & $163.9 \pm 16.6$ & $163.8 \pm 15.9$ & $168.6 \pm 16.6$ & $163.1 \pm 15.9$ & $165.1 \pm 16.0$ & $163.1 \pm 16.0$ \\
\hline Mean SeDBP, mm Hg \pm s.d. & . $\quad 102.0 \pm 5.2$ & $100.3 \pm 4.5$ & $102.4 \pm 5.4$ & $101.4 \pm 5.0$ & $101.1 \pm 5.1$ & $101.7 \pm 5.2$ & $100.8 \pm 4.7$ & $102.1 \pm 5.3$ \\
\hline
\end{tabular}

Abbreviations: BMI, body mass index; BP, blood pressure; NA, not applicable; s.d., standard deviation; SeDBP, seated diastolic BP; SeSBP, seated systolic BP.

Total $n$ for each subgroup and data reported reflect all 12 treatment arms.

with diabetes, was achieved by $56.3 \%$ of patients aged $<65$ years (Figure 2). In patients aged $\geqslant 65$ years, this goal was achieved by fewer patients $(21.2 \%)$ who received combination therapy compared with amlodipine monotherapy $(31.1 \%)$ despite the greater SeBP reductions observed. This discrepancy may be because of the lower number of patients in this subgroup. For example, $43.8 \%$ of patients aged $\geqslant 65$ years who received the amlodipine + olmesartan medoxomil $10+20 \mathrm{mg} \mathrm{day}^{-1}$ regimen achieved BP goal (data not shown). Achievement of the prespecified BP targets of $<140 / 90,<130 / 80$ and $<120 / 80 \mathrm{~mm} \mathrm{Hg}$ was also measured cumulatively through the duration of the study. These targets were achieved at the highest rates in patients who received amlodipine + olmesartan medoxomil combinations that included amlodipine $10 \mathrm{mg} \mathrm{day}^{-1}$, regardless of age. (Supplementary Table 2).

\section{Race}

At week 8/LOCF, changes in mean SeBP were $-28.7 /-15.7$ and $-30.5 /-19.9 \mathrm{~mm} \mathrm{Hg}$ for Black and non-Black patients, respectively, who received amlodipine + olmesartan medoxomil $10+40 \mathrm{mg} \mathrm{day}^{-1}$ (Figure 1). At this dosage, the SeBP changes were significant for combination therapy compared with the monotherapy components for non-Black patients and for Black patients with olmesartan medoxomil but not with amlodipine monotherapy. In non-Black patients, BP goal was achieved by $52.0 \%$ of those who received combination therapy, a greater proportion than observed for the monotherapy groups (Figure 2). More Black patients who received amlodipine $10 \mathrm{mg} \mathrm{day}^{-1}(43.6 \%)$ achieved the BP goal compared with combination therapy comprising amlodipine + olmesartan medoxomil $10+40 \mathrm{mg} \mathrm{day}^{-1}(38.2 \%)$, although this may also be because of the lower number of patients in this subgroup. For example, $45.7 \%$ of Black patients who received the amlodipine + olmesartan medoxomil $10+20 \mathrm{mg} \mathrm{day}^{-1}$ regimen achieved BP goal (data not shown). Regardless of race, combination therapies enabled more patients to achieve the prespecified BP targets of $<140 / 90,<130 / 80$ and $<120 / 80 \mathrm{mmHg}$ compared with monotherapy (Supplementary Table 2).

\section{Diabetes status}

In patients with and without diabetes similar changes in mean SeBP from baseline were observed. At week 8/LOCF, changes in mean SeBP were $-30.3 /-18.4$ and $-30.1 /-19.1 \mathrm{~mm} \mathrm{Hg}$ for patients with and without diabetes, respectively, who received amlodipine + olmesartan medoxomil $10+40 \mathrm{mg} \mathrm{day}^{-1}$ (Figure 1). All SeBP changes were significant for combination therapy compared with the monotherapy components. In patients without diabetes, $55.5 \%$ achieved BP goal $(<140 / 90 \mathrm{~mm} \mathrm{Hg})$ at week $8 / \mathrm{LOCF}$ when treated with combination therapy (Figure 2). The more stringent BP goal of $<130 / 80 \mathrm{~mm} \mathrm{Hg}$ was achieved by $12.5 \%$ of patients with diabetes who received combination therapy. Achievement of the prespecified BP targets of $<140$ / $90,<130 / 80$ and $<120 / 80 \mathrm{~mm} \mathrm{Hg}$ are shown in Supplementary Table 2.

\section{Baseline BMI}

In both BMI subgroups, patients who received amlodipine + olmesartan medoxomil combination 
734
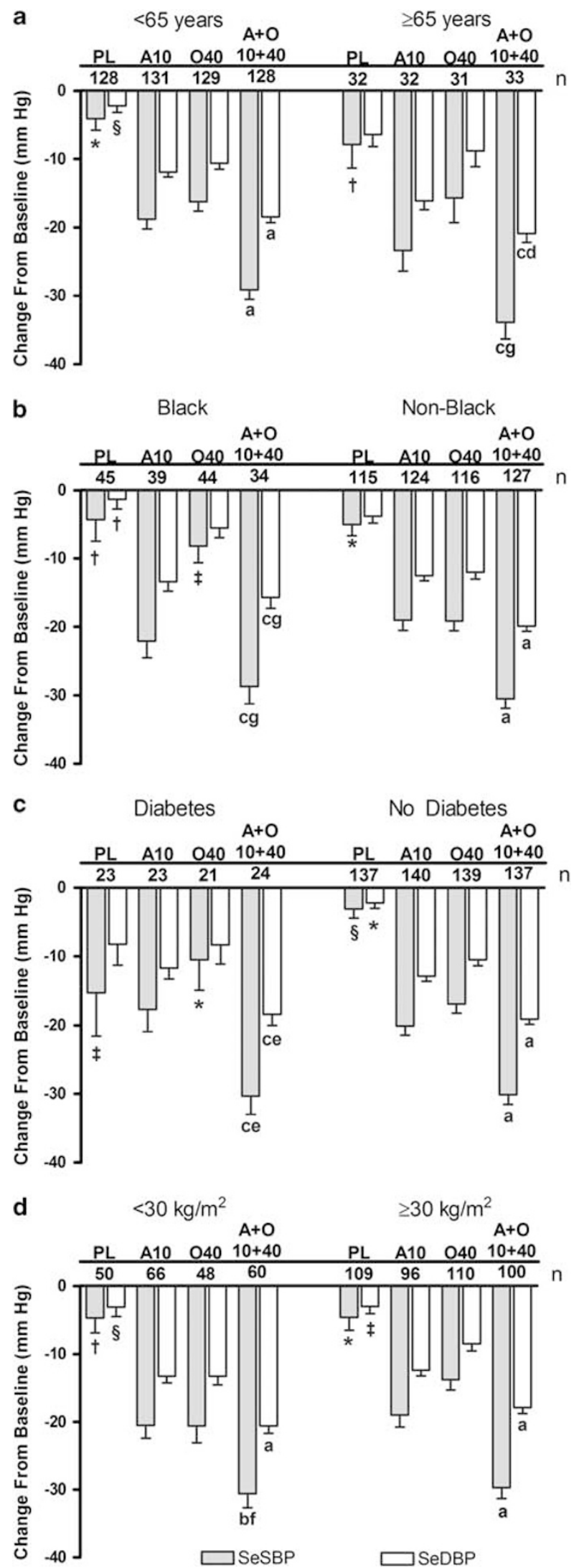

therapy enabled significantly greater reductions in SeDBP and SeSBP than their component monotherapies (Figure 1). At Week 8/LOCF, changes in mean SeBP were $-30.6 /-20.6$ and $-29.7 /$ $-17.9 \mathrm{~mm} \mathrm{Hg}$ for patients with BMI $<30 \mathrm{~kg} \mathrm{~m}^{-2}$ and $\geqslant 30 \mathrm{~kg} \mathrm{~m}^{-2}$, respectively, who received amlodipine + olmesartan medoxomil $10+40 \mathrm{mg} \mathrm{day}^{-1}$ (Figure 1). The BP goal was achieved by similar proportions of patients in each BMI subgroup. For patients treated with combination therapy, $53.3 \%$ of patients with baseline BMI $<30 \mathrm{~kg} \mathrm{~m}^{-2}$ and $46.0 \%$ with baseline $\mathrm{BMI} \geqslant 30 \mathrm{~kg} \mathrm{~m}^{-2}$ achieved $\mathrm{BP}$ goal (Figure 2). There was a trend for more patients with a baseline BMI $<30 \mathrm{~kg} \mathrm{~m}^{-2}$ to achieve BP targets of $<120 / 80$ and $<130 / 80 \mathrm{~mm} \mathrm{Hg}$ compared with patients with a baseline $\mathrm{BMI} \geqslant 30 \mathrm{~kg} \mathrm{~m}^{-2}$ (Supplementary Table 2).

\section{Safety}

When comparing the safety profile obtained in those patients aged $\geqslant 65$ years or $<65$ years, Black or nonBlacks, those with or without diabetes, or in patients with a $\mathrm{BMI} \geqslant 30 \mathrm{~kg} \mathrm{~m}^{-2}$ or $<30 \mathrm{~kg} \mathrm{~m}^{-2}$, no marked differences were observed. There was one serious $\mathrm{AE}$ (cerebrovascular accident) considered to be drug-related, occurring in a Black, obese female patient aged $<65$ years with type II diabetes in the olmesartan medoxomil $20 \mathrm{mg} \mathrm{day}^{-1}$ group. Safety data are reported categorically for all the 12 treatment groups who received placebo, amlodipine monotherapy, olmesartan medoxomil monotherapy and amlodipine + olmesartan medoxomil combination therapy (Table 2).

Age. Among patients aged $\geqslant 65$ years, $7.0 \%$ (27 out of 384) discontinued from the study because of treatment-emergent AEs (TEAEs), 4.2\% (16 out of

Figure 1 Mean reductions in SeSBP and SeDBP from baseline to week 8/LOCF according to subgroup and treatment regimen. (a) Age subgroups; (b) race subgroups; (c) diabetes subgroups; and (d) baseline BMI subgroups. AML, amlodipine; LOCF, last observation carried forward; PL: placebo; A10: amlodipine $10 \mathrm{mg}$; OM40: olmesartan medoxomil $40 \mathrm{mg}$; and A + $010+40$ : amlodipine + olmesartan $10+40 \mathrm{mg}$. Statistics for comparisons to baseline are two-sided. $n$ represents number of patients who received indicated treatment. $P<0.0001$ versus baseline for each SeBP change from baseline unless otherwise noted. ${ }^{*} P<0.01$ versus baseline; 'Not significant versus baseline; ${ }^{\ddagger} P<0.001$ versus baseline; ${ }^{\S} P<0.05$ versus baseline. Statistics for combinations versus monotherapy components used least-squares mean derived from an analysis of covariance model with treatment, subgroup and treatment-by-subgroup interaction as fixed effects and baseline BP as covariate and are one-sided. Symbol for comparison with olmesartan medoxomil monotherapy precedes symbol for comparison with AML monotherapy component. ${ }^{\mathrm{a}} P<0.0001$ versus both monotherapy components; ${ }^{\mathrm{b}} P<0.01$ versus olmesartan medoxomil monotherapy component; ${ }^{\mathrm{c}} P<$ 0.0001 versus olmesartan medoxomil monotherapy component; ${ }^{\mathrm{d}} P<0.025$ versus $A M L$ monotherapy component; ${ }^{\mathrm{e}} P<0.01$ versus AML monotherapy component; ${ }^{\mathrm{f}} P<0.001$ versus AML monotherapy component; ${ }^{\mathrm{g}}$ Not significant versus AML component. Bars represent standard errors of the mean. 


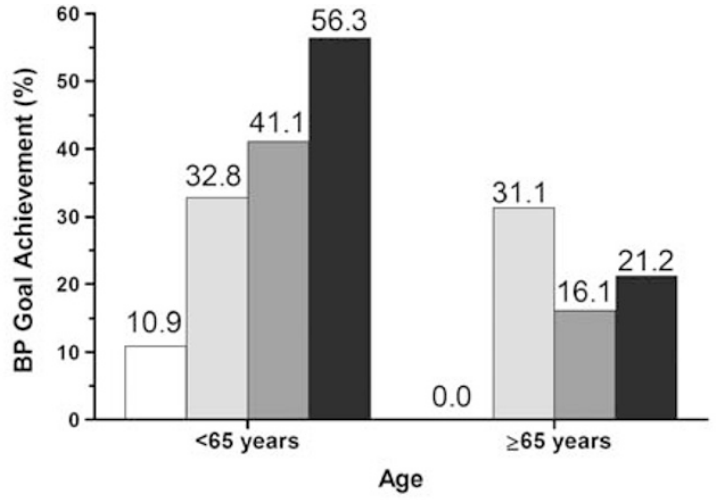

b

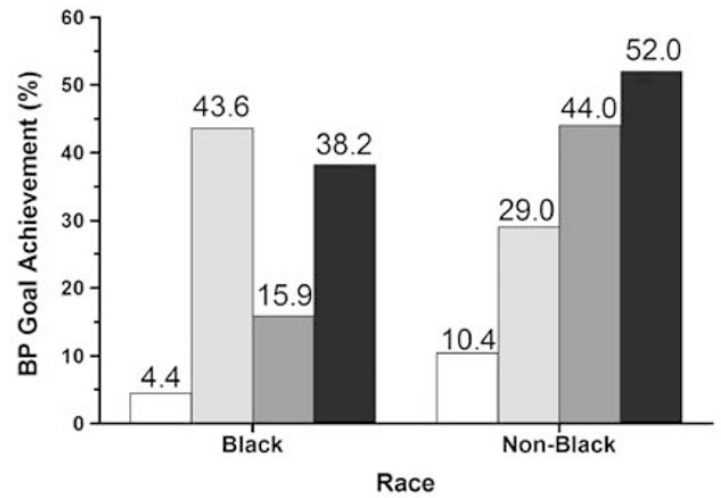

C

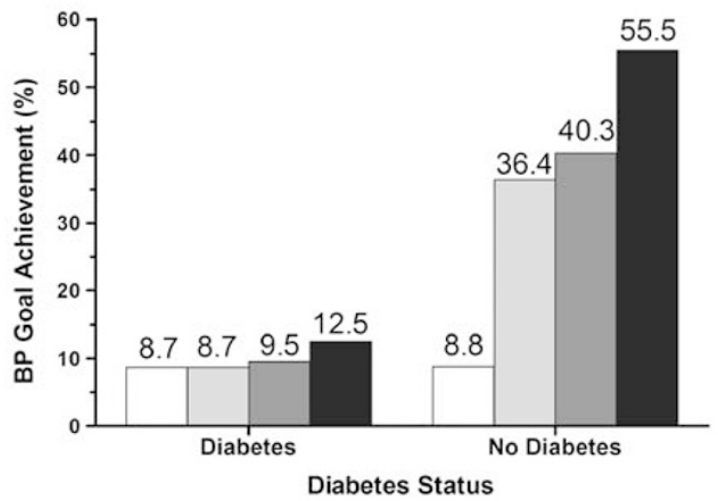

d

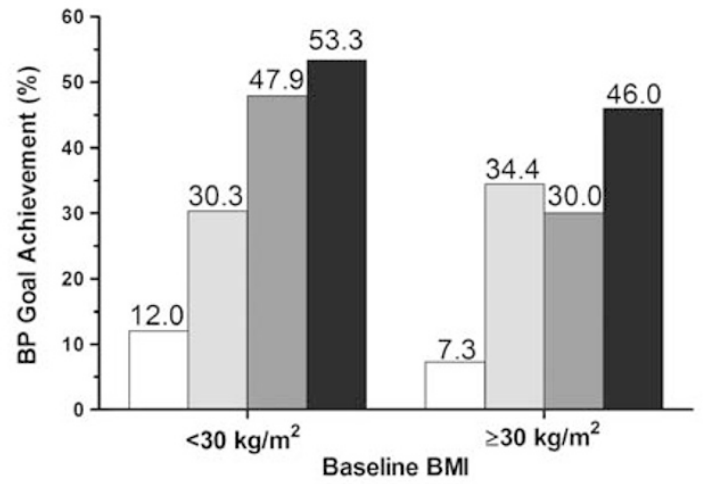

$\square$ Placebo $\square$ AML $10 \mathrm{mg} \square \mathrm{OM} 40 \mathrm{mg} \square \mathrm{AML}+\mathrm{OM} 10+40 \mathrm{mg}$

Figure 2 Proportion of patients reaching BP treatment goal $(<140 /$ $90 \mathrm{~mm} \mathrm{Hg}$ or $<130 / 80 \mathrm{~mm} \mathrm{Hg}$ for patients with diabetes) by week 8/ LOCF according to subgroup and treatment regimen. (a) Age subgroups; (b) race subgroups; (c) diabetes subgroups; and (d) baseline BMI subgroups. AML, amlodipine; BMI, body mass index; LOCF, last observation carried forward; and OM, olmesartan medoxomil.
384) of which were considered drug related. Among patients $<65$ years of age, $5.3 \%$ (82 out of 1556) discontinued because of TEAEs, $3.7 \%$ (58 out of 1556) of which were considered drug related. The number and proportion of specific drug-related TEAEs associated with CCB and/or ARB antihypertensive medications are summarized in Table 2 . Rates of hypotension were similar in both subgroups.

Race. Twenty-one Black patients (4.4\%) discontinued due to TEAEs, $13(2.7 \%)$ of which were considered drug-related. In non-Black patients, 88 $(6.0 \%)$ discontinued due to TEAEs, $61(4.2 \%)$ of which were considered to be drug-related. The number and proportion of specific TEAEs associated with CCB and/or ARB antihypertensive medications are summarized in Table 2 . The incidence of oedema was lower in non-Black patients that received combination therapy, compared with amlodipine monotherapy. However, as with the total study cohort $^{19}$ oedema was lower in patients with diabetes who received amlodipine + olmesartan medoxomil $10+40 \mathrm{mg} \mathrm{day}^{-1}$ compared with amlodipine $10 \mathrm{mg} \mathrm{day}^{-1}$ monotherapy (data not shown).

Diabetes status. Among patients with diabetes, 12 $(4.6 \%)$ discontinued because of TEAEs, $9(3.4 \%)$ of which were considered to be drug related. Among patients without diabetes, $97(5.8 \%)$ discontinued because of TEAEs and $65(3.9 \%)$ were considered to be drug related. The number and proportion of specific TEAEs associated with CCB and/or ARB antihypertensive medications are summarized in Table 2. In general, patients with diabetes who received combination therapy had slightly higher incidences of oedema compared with respective monotherapies.

Baseline BMI. In patients with a baseline $\mathrm{BMI} \geqslant 30 \mathrm{~kg} \mathrm{~m}^{-2}, 72(5.7 \%)$ discontinued because of TEAEs and $54(4.3 \%)$ were considered to be drug related. In patients with a BMI $<30 \mathrm{~kg} \mathrm{~m}^{-2}, 37$ and $20(5.5$ and $3.0 \%)$ discontinued because of TEAEs and drug-related TEAEs, respectively. The number and proportion of specific TEAEs associated with CCB and/or ARB antihypertensive medications are summarized in Table 2.

\section{Discussion}

Achieving target BP is a continuing challenge for the management of patients with hypertension. As such, it is acknowledged that the majority of patients, especially those with multiple risk factors, will require combination therapy with at least two antihypertensive agents to achieve optimal BP control. ${ }^{1,2}$ Nevertheless, evidence indicates that patients are often not treated to their target BP goal. ${ }^{7,20}$ The combination of amlodipine + olmesartan medoxomil 


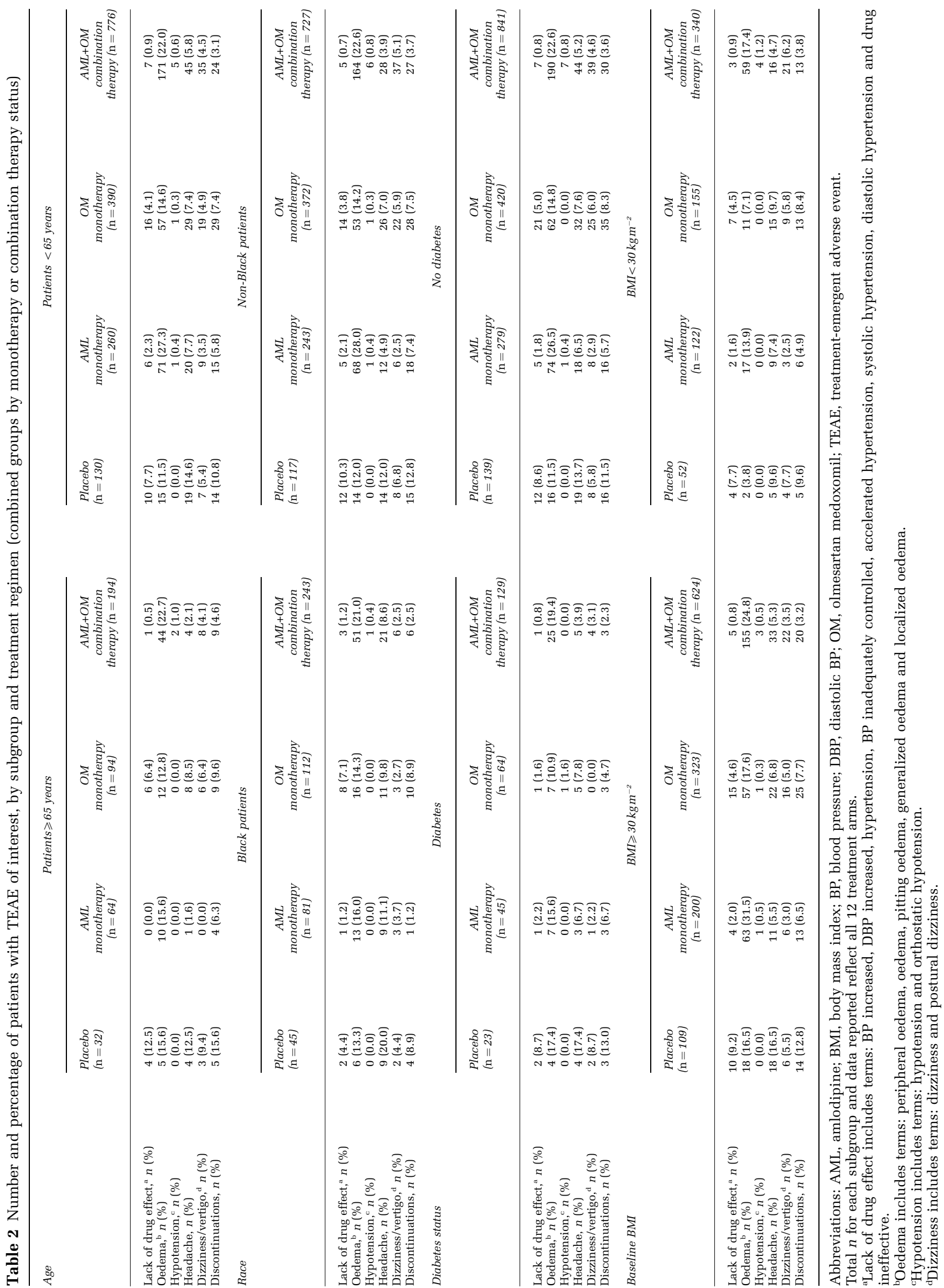


lowers BP through different but complementary mechanisms of action. This results in additive BPlowering effects through multiple inhibitory mechanisms, complementing the efficacy of the other antihypertensive agent and may offer wider benefits over and above BP control. ${ }^{14,15}$

In this study, there was a consistent dose-response effect across a range of prespecified patient groups, analysed according to age, race, diabetes status and BMI. Across all subgroups, high doses of amlodipine + olmesartan medoxomil combinations produced greater reductions in BP than either of the monotherapy components, allowing a greater proportion of these perceived difficult-to-treat patients to achieve the target BP goal. For the primary endpoint, amlodipine + olmesartan medoxomil $10+40 \mathrm{mg}$ day $^{-1}$ produced the greatest reductions in mean SeDBP at week 8/LOCF in all subgroups. However, unlike the overall cohort, it should be noted that this study was not powered to show statistical differences between combination therapy and its component monotherapies within the subgroups.

Age did not appear to affect the magnitude of SeDBP reduction, and there were generally greater reductions in patients that received combination therapy compared with monotherapy. Numerically greater reductions in SeSBP were seen in patients $\geqslant 65$ years of age compared with those aged $<65$ years. However, the $10 \mathrm{~mm} \mathrm{Hg}$ higher baseline SeSBP in patients aged $\geqslant 65$ years likely contributed to the lower proportions of these patients achieving the recommended BP goal of $<140 / 90 \mathrm{~mm} \mathrm{Hg}$ or $<130 / 80 \mathrm{~mm} \mathrm{Hg}$ in patients with diabetes.

Black patients tended to have higher baseline BP than the non-Black patients. When treated with olmesartan medoxomil monotherapy, Blacks had numerically lower reductions in mean SeDBP and SeSBP compared with non-Blacks. However, the addition of amlodipine in the combination treatment groups provided comparable BP reductions in Blacks and non-Blacks. Greater reductions were seen with amlodipine + olmesartan medoxomil $10+40 \mathrm{mg} \mathrm{day}^{-1}$, where mean BP reductions reached approximately $29 / 16 \mathrm{~mm} \mathrm{Hg}$ in the Black subgroup and $31 / 20 \mathrm{~mm} \mathrm{Hg}$ in non-Black patients. In both race subgroups, more patients on combination therapy achieved their BP goal compared with patients on monotherapy.

Similar overall reductions in mean SeDBP and SeSBP were observed in patients with and without diabetes. However, the lower BP goal of $<130 /$ $80 \mathrm{~mm} \mathrm{Hg}$ and the higher baseline $\mathrm{BP}$ resulted in fewer patients with diabetes achieving the BP goal, compared with patients without diabetes who had a less stringent goal $(\mathrm{BP}<140 / 90 \mathrm{~mm} \mathrm{Hg})$. These results support the assertion that patients with diabetes are likely to require $>2$ antihypertensive drugs to achieve the BP goals recommended by the American Diabetes Association. ${ }^{6,13}$

Similar overall mean SeBP reductions from baseline were also observed in patients irrespective of baseline BMI. Generally, more patients achieved BP goal when administered combination therapy of amlodipine + olmesartan medoxomil compared with either drug as monotherapy. The incidence of oedema was greater in patients with a baseline $\mathrm{BMI}>30 \mathrm{~kg} \mathrm{~m}^{-2}$. This may have been due, in part, to obesity confounding the diagnosis of oedema.

Overall, combinations of amlodipine + olmesartan medoxomil generally produced greater BP reductions than component monotherapies regardless of age, race, diabetes status or BMI. The amlodipine + olmesartan medoxomil $10+40 \mathrm{mg} \mathrm{day}^{-1}$ combination produced the greatest reductions in mean SeDBP in all subgroups and in SeSBP in all subgroups except nonBlacks. In non-Blacks, the greatest reduction in mean SeSBP was produced by amlodipine + olmesartan medoxomil $10+20 \mathrm{mg} \mathrm{day}^{-1}$ (data not shown). In addition, safety and tolerability profiles were similar when comparing subgroups with difficult-to-treat hypertension with their counterparts with more easily treated disease as well as for the monotherapy-treated cohorts. In these subgroups, as with the total study cohort, ${ }^{19}$ oedema was higher in patients who received amlodipine $10 \mathrm{mg}$ day $^{-1}$ monotherapy compared with amlodipine + olmesartan medoxomil $10+40 \mathrm{mg}$ day $^{-1}$ (data not shown). A fixed-dose combination of amlodipine + olmesartan medoxomil has been approved by the US Food and Drug Administration as initial therapy for patients with hypertension unlikely to reach BP goal on monotherapy and may provide more flexibility for the successful treatment of hard-totreat hypertensive patients.

What is known about this topic

- The prevalence of hypertension is higher in those aged $\geqslant 65$ years, Blacks, patients with type II diabetes and patients with a body mass index (BMI) $\geqslant 30 \mathrm{~kg} \mathrm{~m}^{-2}$.

- These subgroups often require two or more antihypertensive agents to achieve Joint National Committee on Prevention, Detection, Evaluation, and Treatment of High Blood Pressure (JNC 7)-recommended blood pressure (BP) goals $(<140 / 90 \mathrm{~mm} \mathrm{Hg}$ or $<130$ / $80 \mathrm{~mm} \mathrm{Hg}$ in patients with diabetes).

What this study adds

- The combination of amlodipine+olmesartan medoxomil enabled significant reductions in mean seated systolic BP (SeSBP) and mean seated diastolic BP (SeDBP) compared with baseline in these subgroups.

- Combinations of amlodipine+olmesartan medoxomil enabled greater proportions of patients to achieve BP goal compared with either agent administered as monotherapy in patients aged $\geqslant 65$ years, Blacks and patients with a $\mathrm{BMI} \geqslant 30 \mathrm{~kg} \mathrm{~m}^{-2}$.

- In these subgroups, the combinations of amlodipine+olmesartan medoxomil had safety profiles similar to the constituent monotherapies.

\section{Conflict of interest}

Steven G Chrysant, MD, has received grant/research support from, has served as a consultant for, and has 
served on the Speaker's Bureau for Daiichi Sankyo Pharma Development. James Lee, PhD; Michael Melino, PhD; Sulekha Karki, BAMS; and Reinilde Heyrman, MD, are all employees of Daiichi Sankyo Pharma Development.

\section{Acknowledgements}

This study was sponsored by Daiichi Sankyo, Inc. We thank Jennifer M Kulak, PhD, and Christopher J Jones, $\mathrm{PhD}$, of Wolters Kluwer, for providing editorial assistance in the preparation of this manuscript.

\section{References}

1 Chobanian AV, Bakris GL, Black HR, Cushman WC, Green LA, Izzo Jr JL et al. Seventh report of the Joint National Committee on Prevention, Detection, Evaluation, and Treatment of High Blood Pressure. Hypertension 2003; 42: 1206-1252.

2 Mancia G, De Backer G, Dominiczak A, Cifkova R, Fagard R, Germano G et al. 2007 Guidelines for the Management of Arterial Hypertension: The Task Force for the Management of Arterial Hypertension of the European Society of Hypertension (ESH) and of the European Society of Cardiology (ESC). J Hypertens 2007; 25: 1105-1187.

3 Lewington S, Clarke R, Qizilbash N, Peto R, Collins R. Age-specific relevance of usual blood pressure to vascular mortality: a meta-analysis of individual data for one million adults in 61 prospective studies. Lancet 2002; 360: 1903-1913.

4 Douglas JG, Bakris GL, Epstein M, Ferdinand KC, Ferrario C, Flack JM et al. Management of high blood pressure in African Americans: consensus statement of the Hypertension in African Americans Working Group of the International Society on Hypertension in Blacks. Arch Intern Med 2003; 163: 525-541.

5 Rosamond W, Flegal K, Furie K, Go A, Greenlund K, Haase $\mathrm{N}$ et al. Heart disease and stroke statistics-2008 update: a report from the American Heart Association Statistics Committee and Stroke Statistics Subcommittee. Circulation 2008; 117: e25-e146.

6 Arauz-Pacheco C, Parrott MA, Raskin P. The treatment of hypertension in adult patients with diabetes. Diabetes Care 2002; 25: 134-147.

7 Ong KL, Cheung BM, Man YB, Lau CP, Lam KS. Prevalence, awareness, treatment, and control of hypertension among United States adults 1999-2004. Hypertension 2007; 49: 69-75.
8 Wong ND, Lopez VA, L'Italien G, Chen R, Kline SE, Franklin SS. Inadequate control of hypertension in US adults with cardiovascular disease comorbidities in 2003-2004. Arch Intern Med 2007; 167: 2431-2436.

9 O'Rourke MF, Safar ME. Relationship between aortic stiffening and microvascular disease in brain and kidney: cause and logic of therapy. Hypertension 2005; 46: 200-204.

10 Pessina AC. Target organs of individuals with diabetes caught between arterial stiffness and damage to the microcirculation. J Hypertens Suppl 2007; 25(Suppl 1): S13-S18.

11 Watson KE. Cardiovascular risk reduction among African Americans: a call to action. J Natl Med Assoc 2008; 100: 18-26.

12 Sarzani R, Salvi F, Dessi-Fulgheri P, Rappelli A. Reninangiotensin system, natriuretic peptides, obesity, metabolic syndrome, and hypertension: an integrated view in humans. J Hypertens 2008; 26: 831-843.

13 American Diabetes Association. Standards of medical care in diabetes-2008. Diabetes Care 2008; 31(Suppl 1): S12-S54.

14 Messerli FH. Vasodilatory edema: a common side effect of antihypertensive therapy. Curr Cardiol Rep 2002; 4: 479-482.

15 Weir MR. Incidence of pedal edema formation with dihydropyridine calcium channel blockers: issues and practical significance. J Clin Hypertens (Greenwich) 2003; 5: 330-335.

16 Volpe M. Hypertension therapy: mixing, matching, and meeting targets. Adv Ther 2004; 21: 107-122.

17 Jamerson K, Weber MA, Bakris GL, Dahlof B, Pitt B, Shi V et al. Benazepril plus amlodipine or hydrochlorothiazide for hypertension in high-risk patients. $N$ Engl J Med 2008; 359: 2417-2428.

18 Kjeldsen SE, Jamerson KA, Bakris GL, Pitt B, Dahlof B, Velazquez EJ et al. Predictors of blood pressure response to intensified and fixed combination treatment of hypertension: the ACCOMPLISH study. Blood Press 2008; 17: 7-17.

19 Chrysant S, Melino M, Karki S, Lee J, Heyrman R. The combination of olmesartan medoxomil and amlodipine besylate in controlling high blood pressure: $\mathrm{COACH}$, a randomized, double-blind, placebo-controlled, 8-week factorial efficacy and safety study. Clin Ther 2008; 30: 587-604.

20 McInnes GT. How important is optimal blood pressure control? Clin Ther 2004; 26(Suppl A): A3-A11.

() This work is licensed under the Creative

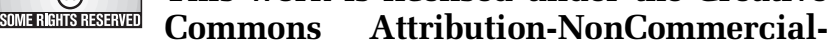
No Derivative Works 3.0 Unported License. To view a copy of this license, visit http://creativecommons. org/licenses/by-nc-nd/3.0/

Supplementary Information accompanies the paper on the Journal of Human Hypertension website (http://www.nature.com/jhh) 